\title{
Modified simple decompression in the treatment of cubital tunnel syndrome: avoiding ulnar nerve subluxation
}

\author{
Descompressão simples modificada no tratamento da síndrome do túnel cubital: evitando \\ subluxação do nervo ulnar
}

Marcus André Acioly 1,2, Amanda Mendes Soares², Mariana Lopes de Almeida², Renata Barbosa Egon Daxbacher ${ }^{3}$, Carlos Henrique Carvalho ${ }^{4}$

\begin{abstract}
Objective: In this study, we propose a modification to the simple decompression technique that contains the ulnar nerve in the cubital fossa, thus preventing subluxation during forearm flexion movements. Methods: Five consecutive patients with leprosy-associated cubital tunnel syndrome underwent surgery with the modified technique between July 2011 and October 2012. Results: The most common symptoms were neuropathic pain and sensory changes (both 60\%). On the McGowan scale, three patients maintained their preoperative score and two patients improved by two points, while on the Louisiana State University Health Sciences Center scale, two patients maintained the same scores, two improved by two points, and one improved by one point. Four patients were able to discontinue corticosteroid use. The mean follow-up time was 25.6 months (range 2-48 months). There were no recurrences or subluxations in the long-term. Conclusion: This alternative technique resulted in excellent functional results, as well as successful withdrawal from corticosteroids. Furthermore, it resulted in no ulnar nerve subluxations.
\end{abstract}

Keywords: cubital tunnel syndrome; decompression; leprosy; peripheral nerves; ulnar nerve.

\section{RESUMO}

Objetivo: Neste manuscrito apresentamos uma modificação da técnica de descompressão simples do nervo ulnar no túnel cubital que impede a subluxação do nervo em movimentos de flexão do antebraço. Métodos: Foram incluídos cinco pacientes consecutivos acometidos por síndrome do túnel cubital (Hanseníase) submetidos à cirurgia entre 2011 e 2012. Resultados: Os sintomas mais comuns foram dor neuropática e alterações sensitivas (60\%). No pós-operatório, três pacientes mantiveram o mesmo escore e dois melhoraram dois pontos na escala de McGowan, enquanto na escala Louisiana State University Health Sciences Center, dois pacientes mantiveram o mesmo escore, dois melhoraram dois pontos e um melhorou um ponto. Os corticosteróides foram descontinuados em quatro pacientes. 0 tempo médio de seguimento foi 25,6 meses (variação 2-48 meses). Não foram observadas recorrência ou subluxação no longo prazo. Conclusões: A técnica alternativa apresentou excelentes resultados funcionais e foi bem sucedida na retirada dos corticosteróides. Ademais, subluxações do nervo ulnar não foram observadas.

Palavras-chave: síndrome do túnel ulnar; descompressão; hanseníase; nervos periféricos; nervo ulnar.

Cubital tunnel syndrome (CuTS) is the second most common entrapment neuropathy of the upper limb in adults ${ }^{1,2,3,4}$. It is categorized into two major etiologies, namely primary or idiopathic, and secondary or symptomatic ${ }^{1}$. The idiopathic form is characterized by the absence of bone or nerve structural abnormalities, even though some predisposing factors, such as ulnar nerve luxation, presence of the anconeus epitrochlearis muscle, or deformities of the medial head of the triceps muscle, can be documented ${ }^{1}$.

Secondary CuTS, however, is caused by elbow joint abnormalities and space occupying lesions within or in the vicinity of the cubital tunnel ${ }^{1}$. Leprosy is still a major

\footnotetext{
'Universidade Estadual do Rio de Janeiro, Disciplina de Neurocirurgia, Rio de Janeiro RJ, Brasil;

${ }^{2}$ Universidade Federal do Rio de Janeiro, Disciplina de Neurocirurgia, Rio de Janeiro RJ, Brasil;

${ }^{3}$ Universidade Estadual do Rio de Janeiro, Disciplina de Dermatologia, Rio de Janeiro RJ, Brasil;

${ }^{4}$ Schwarzwald Baar Klinikum, Division of Neurosurgery, Villigen-Schwennigen, Germany.
}

Correspondence: Marcus André Acioly; Departamento de Cirurgia, Disciplina de Neurocirurgia; Hospital Universitário Clementino Fraga Filho / UFRJ; Rua Rodolpho Paulo Rocco, 255; Cidade Universitária - Itha; 21941-213 Rio de Janeiro RJ, Brasil; E-mail: marcusacioly@yahoo.com.br

Conflict of interest: There is no conflict of interest to declare.

Received 10 August 2016; Received in final form 12 December 2016; Accepted 30 December 2016. 
cause of peripheral neuropathy worldwide, especially in South East Asia, Central and South America ${ }^{5}$. In Brazil, about $79 \%$ of leprosy patients have ulnar nerve impairment ${ }^{6}$, which is related to nerve thickening as a result of the inflammatory process triggered by the intraneural invasion of $M$. leprae or its antigens; this, in turn, increases the risk of $\mathrm{CuTS}^{7,8}$.

Cubital tunnel syndrome is mostly treated clinically, but surgical treatment is recommended for patients who are progressively symptomatic and do not show clinical and electrophysiological improvement after weeks of conservative management ${ }^{1}$. For leprosy-associated CuTS, surgery is indicated in cases of clinical refractoriness after four weeks of conservative treatment, in those who have nerve abscesses, subintrant neuropathy, subluxing ulnar nerve, or contraindications to corticosteroid use ${ }^{9}$. At present, three groups of techniques are used most frequently, namely simple decompression, medial epicondilectomy and anterior transposition (subcutaneous, intramuscular and submuscular) ${ }^{2,10}$. Even so, the best technique has yet to be defined, both for idiopathic and leprosy-associated CuTS. Herein, we describe a modified version of the simple ulnar nerve decompression technique that aims to avoid nerve subluxation.

\section{METHODS}

\section{Patients}

Five consecutive patients with leprosy-associated CuTS underwent surgery with the modified technique between July 2011 and October 2012. Four of the patients were male, and the mean age was 40.6 years. Disease duration varied between 10 months and seven years. The most common symptoms were neuropathic pain and sensory changes (both 60\%) (Table). Surgery was indicated due to subintrant neuropathy following three unsuccessful attempts of prednisone withdrawal. Preoperative ulnar nerve instability was not documented in any patient during physical examination. All patients underwent electrophysiological evaluation to confirm the diagnosis of ulnar neuropathy. Informed consent was obtained from each patient for the publication of this study. The modified technique was performed solely in leprosy-associated CuTS. During this time frame, there were no idiopathic cases considered for surgery.

\section{Surgical technique}

The surgery was performed on an outpatient basis with local anesthesia and sedation. The patient was positioned supine with the arm extended and abducted at $90^{\circ}$ to the shoulder and a supine forearm. The surgical technique was performed as described by Huang et al. ${ }^{11}$ with some modifications. In short, an incision of about $6-8 \mathrm{~cm}$ was drawn on the retro-epicondylar region following the projection of the ulnar nerve, taking special care not to damage the medial antebrachial cutaneous nerve. Once the incision was made, and the brachial fascia raised and perforated using a curved mosquito hemostat, the ulnar nerve was readily identified. The fascia was cut with scissors in the craniocaudal direction and the nerve exposed beneath the brachial fascia that involves the medial head of the triceps muscle. A small cross fragment of the loose fascia approximately 5-mm wide and proximal to the medial epicondyle was preserved in order to maintain the ulnar nerve overlying the triceps muscle. Next, the surgeon opened the cubital tunnel roof, thus decompressing the site where maximum nerve compression occurs in most cases. Afterwards, the distal skin edge was raised and the fingertip maneuver done in order to verify adequate decompression. In that case, any residual compression was sectioned. Next, the proximal skin edge was elevated, and the compression sectioned up to the medial intermuscular septum. Internal neurolysis was not necessary for this procedure, and the nerve was kept in its bed, thus avoiding circumferential decompression. The fingertip maneuver was then performed cranially. After the decompression process, ulnar subluxation maneuver was assessed to assure that the nerve remains in the cubital fossa due to the fascial restraint (Figure). Hemostasis was performed meticulously and wound closure done on two layers: subcutaneous and skin. Finally, a bandage and sling were applied to the outstretched arm. Corticosteroids were recommended (prednisone - $1 \mathrm{mg} / \mathrm{kg}$ ) in the immediate postoperative period ${ }^{9}$, and removed gradually over two to three months in the outpatient clinic.

\section{Clinical outcomes}

Patient functional status was evaluated by the use of the McGowan $^{12}$ and Louisiana State University Health Sciences Center $^{13}$ scales by independent investigators (RB, ED). We also assessed whether the patient used corticosteroids pre- and postoperatively, and whether there was pre- and postoperative subluxation.

\section{RESULTS}

One patient developed a small suture dehiscence postoperatively. In terms of functional status, three patients maintained their preoperative McGowan score, while two patients improved by two points, and on the Louisiana State University Health Sciences Center scale, two patients maintained the same scores, two improved by two points, and one improved by one point. Four patients were able to discontinue corticosteroid use. The mean follow-up time was 25.6 months (range $2-48$ months). There were no recurrences or subluxations in the long-term. One patient was referred back to primary care at two months postoperatively, and was lost to the follow up (Patient 5, Table). 


\section{DISCUSSION}

We demonstrated a modification of the traditional simple decompression technique with the aim of preventing subluxation of the ulnar nerve. The modification consists of preserving a fragment of the loose brachial fascia of the triceps muscle that is proximal to the medial epicondyle; this fragment holds the ulnar nerve in the cubital fossa during forearm flexion, which therefore prevents nerve subluxation. Long-term evaluation confirmed the clinical efficacy by demonstrating improvement in the functional scores and withdrawal of corticosteroids.

The best surgical technique for ulnar nerve decompression has not yet been established. In 2007, Zlowodzki et al. ${ }^{4}$ conducted a meta-analysis on randomized, controlled trials comparing the simple decompression technique with the anterior transposition technique (submuscular or subcutaneous). They found no significant differences in terms of motor nerve-conduction velocity and postoperative clinical scores, which supports the use of a simple
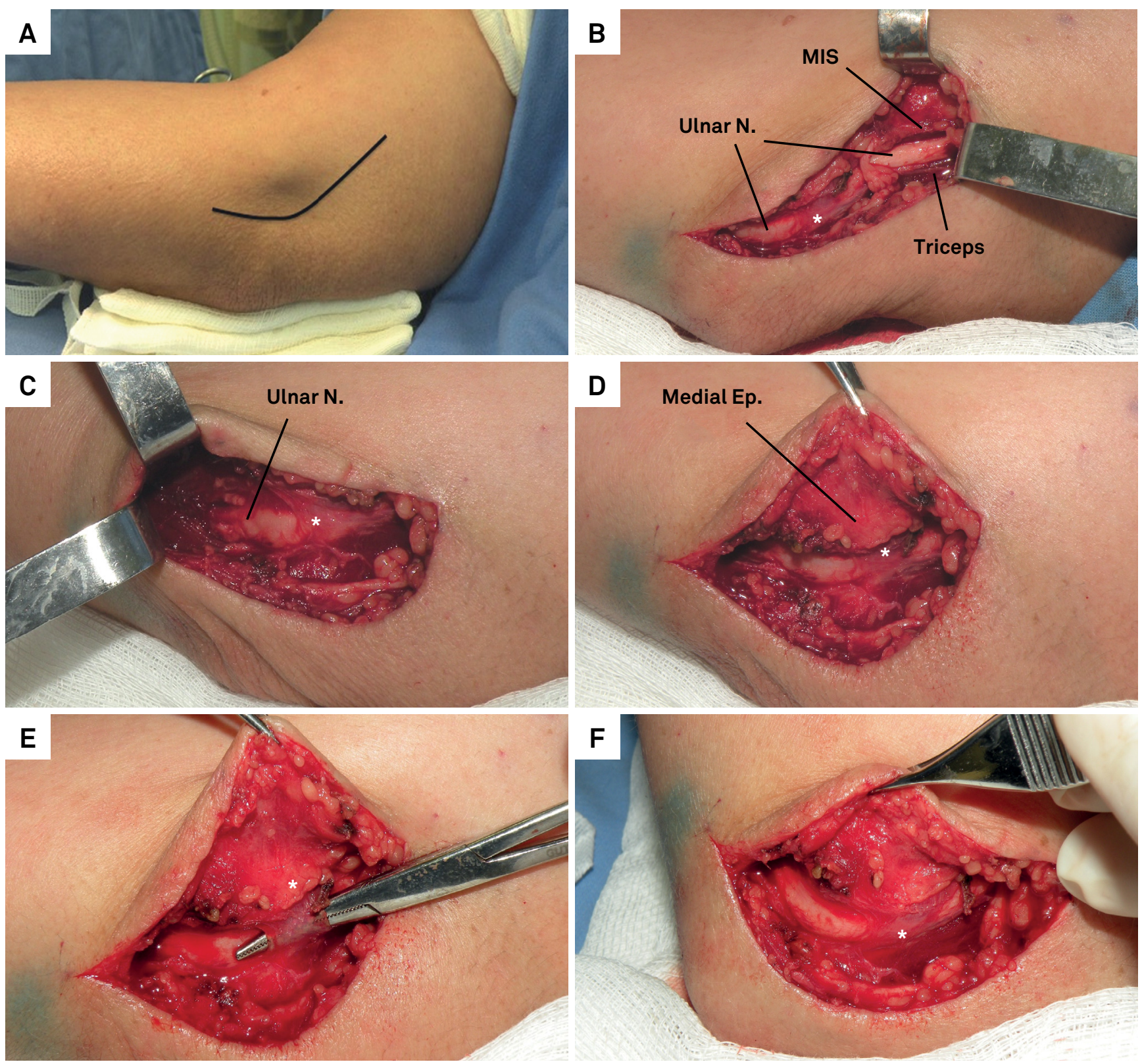

Figure. Modified simple decompression of the ulnar nerve (right elbow, medial view). A. Solid line indicates the planned skin incision. B. After the opening of the deep fascia, a 5-mm cross fragment of the loose fascia over (asterisk) the medial head of the triceps muscle (Triceps) is preserved in order to restrain the ulnar nerve (Ulnar N.) over its bed. Proximal decompression is taken to the level of the medial intermuscular septum (MIS) and the arcade of Struthers (not demonstrated). C. Distally, adequate decompression is obtained by opening the roof of the cubital tunnel and the deep flexor-pronator aponeurosis. D and E. Final aspect after complete decompression. Note the relaxed position of the ulnar nerve, which remained posterior to the medial epicondyle (Medial Ep.). F. During maximal elbow flexion for testing subluxation, the loose fascia (asterisk) prevents the anterior projection of the ulnar nerve and, therefore, nerve instability. 


\begin{tabular}{|c|c|c|c|c|c|c|c|c|c|c|c|}
\hline \multirow{2}{*}{ Patient } & \multirow{2}{*}{$\begin{array}{l}\text { Age/ } \\
\text { Gender }\end{array}$} & \multirow{2}{*}{ Preop symptoms } & \multirow{2}{*}{ Side } & \multirow{2}{*}{$\begin{array}{l}\text { Time of } \\
\text { disease } \\
\text { (mo) }\end{array}$} & \multicolumn{2}{|c|}{ McGowan } & \multicolumn{2}{|c|}{ LSUHMC } & \multirow{2}{*}{$\frac{\text { F-up }}{(\mathrm{mo})}$} & \multirow{2}{*}{ Outcome } & \multirow{2}{*}{ Medication } \\
\hline & & & & & Preop & Postop & Preop & Postop & & & \\
\hline 1 & $33 / M$ & $\begin{array}{c}\text { Neuropathic pain, } \\
\text { paresthesia, hand } \\
\text { weakness }\end{array}$ & $\mathrm{L}$ & 39 & 2 & 2 & 4 & 4 & 48 & $\begin{array}{l}\text { Complete pain } \\
\text { relief, no recurrence }\end{array}$ & $\begin{array}{c}\text { GBP, } \\
\text { Nortryptiline, } \\
\text { no prednisone }\end{array}$ \\
\hline 2 & $36 / \mathrm{M}$ & Neuropathic pain & L & 10 & 2 & 2 & 3 & 4 & 18 & $\begin{array}{l}\text { Complete pain } \\
\text { relief, no recurrence }\end{array}$ & None \\
\hline 3 & $55 / F$ & Paresthesia & $\mathrm{R}$ & 60 & 2 & 0 & 4 & 5 & 42 & $\begin{array}{l}\text { Complete pain } \\
\text { relief, no recurrence }\end{array}$ & $\begin{array}{c}\text { GBP, } \\
\text { amytriptiline, } \\
\text { azathioprine, } \\
\text { no prednisone }\end{array}$ \\
\hline 4 & $30 / \mathrm{M}$ & Paresthesia & $\mathrm{L}$ & 84 & 2 & 0 & 3 & 5 & 18 & $\begin{array}{l}\text { Complete pain } \\
\text { relief, no recurrence }\end{array}$ & None \\
\hline 5 & $49 / M$ & Neuropathic pain & $\mathrm{R}$ & 36 & 2 & 2 & 4 & 4 & 2 & $\begin{array}{l}\text { Complete pain } \\
\text { relief, no recurrence }\end{array}$ & Prednisone \\
\hline
\end{tabular}

M: Male; F: female; L: left; R: right; mo: months; Preop: preoperative; Postop: postoperative; LSUHMC: Lousiana State University Health Medical Center; F-up: follow-up; GBP: gabapentin.

decompression technique, even for moderate-to-severe symptomatic patients. Generally, simple decompression is preferred for being less complex and requiring a smaller incision, which causes less tissue damage, preserves nerve vascularization and requires less rehabilitation time $e^{4,10,11}$.

On the other hand, simple decompression does not contain the nerve in the cubital fossa during flexion, thus enabling subluxation. In such cases, most surgeons choose anterior transposition ${ }^{4,14,15,16}$. The aim of this technique is to move the nerve anteriorly along the elbow's flexion axis in order to decrease intraneural pressure, to prevent the nerve from sliding over the medial epicondyle, and therefore to avoid nerve irritation ${ }^{4,14}$. However, it requires extensive dissection, places the vascular supply of the nerve at risk ${ }^{4}$, and is associated with higher complication rates ${ }^{10,16,17}$.

Some nonrandomized studies addressed a nerve-stability based approach, in which anterior transposition was considered in cases of intraoperative subluxation (22.5\% to $27 \%$ occurrence) $)^{14,15}$. Such a tailored approach was demonstrated to be a safe and effective procedure associated with excellent clinical outcomes in the long-term ${ }^{14,15}$. Besides, Bimmler and Meyer ${ }^{16}$ reported better functional results for patients suffering from ulnar nerve instability treated with anterior submuscular transposition. The best evidence available, however, does not support such an approach, since there is no difference in outcome between simple decompression or subcutaneous transposition in cases of intraoperative ulnar nerve instability ${ }^{10}$.

Regarding leprosy-associated CuTS, Husain ${ }^{8}$ published the largest study involving 772 patients who were unresponsive to corticosteroid treatment. There was no mention of either pre- or postoperative ulnar nerve subluxation in that study, though. Pain relief was observed in all patients, whereas sensory and motor functions improved to normal levels in approximately half of the patients, after external and internal neurolysis, together with medial epicondilectomy in selected cases ${ }^{8}$. Our results demonstrated a similar pain relief, together with improvement by two grades in $40 \%$ of the patients on both functional scales, after simple nerve decompression.

Considering that the course of postoperative ulnar nerve instability is widely unknown for both idiopatic and leprosy-associated CuTS, such a modifiable causative mechanism should be avoided. The technique presented here aims to prevent ulnar nerve subluxation in patients with a high risk of intraoperative instability (e.g., patients with thicker nerves and/or a shallow ulnar groove). Nevertheless, this technique must be planned in order to preserve the loose fascia of the triceps muscle. A new rescue alternative was recently presented by Lane and Greenberg ${ }^{18}$ in a case of minimal subluxation. The ulnar nerve was stabilized using a fragment of the fascia of the flexor-pronator mass, which was transposed posteriorly in order to contain the nerve in its bed, thus preventing it from sliding over the medial epicondyle $^{18}$. The patient was asymptomatic in the long-term (after 3.5 years) and no subluxation was reported ${ }^{18}$. Thus, both techniques represent simple alternatives for decompressing and stabilizing the nerve in the cubital fossa while preventing subluxation.

To some, the preservation of a small fragment of the fascia suggests that the roof of the cubital tunnel is not completely open and that the compression point is maintained, which would constitute a clear limitation of the technique presented. According to Palmer and Hughes ${ }^{19}$, the ulnar nerve path has five sites that are potentially vulnerable to compression: the arcade of Struthers, the medial intermuscular septum, the medial epicondyle, the cubital tunnel itself, and the deep flexor-pronator aponeurosis. Given that in CuTS the main cause of nerve compression is the roof of the tunnel itself, which is composed of the aponeurosis of the flexor carpi ulnaris muscle 
and the retinaculum of the cubital tunnel (also known as Osborne ligament $)^{20}$, the fragment of maintained fascia is not part of the compressive sites described above, thereby refuting the idea that a compression point is maintained during this procedure.

\section{Study limitations}

One limitation of the current study is the small number of patients. Another issue is that all of our patients had leprosy-associated CuTS. It is, therefore, not possible to attribute the obtained results to cases where the cause is idiopathic. Even so, it should be noted that ulnar nerves in leprosy are considerably thicker than idiopathic ones, which indicates the potential role of the modified technique in primary CuTS as well. Additionally, we evaluated the clinical scores of the McGowan and Louisiana State University Health Sciences Center, which are based mainly on subjective criteria of sensation and strength assessment. Motornerve and sensory-nerve conduction velocities, together with disease-specific clinical outcome measures would present a more objective assessment of our results. Finally, we assessed nerve instability by physical examination. Even though dynamic ultrasound is an effective diagnostic tool for detecting the etiology of CuTS, the correlation between ulnar nerve instability by imaging and pre- or postoperative clinical examination is still lacking in the literature ${ }^{21,22}$.
Therefore, it is unclear whether its use could detect subclinical instability, especially in the absence of intraoperative ulnar nerve subluxation.

In conclusion, The present study describes a modification of the simple decompression technique aimed to avoid cases of intra- and postoperative subluxation. There were no cases of subluxation among the patients tested and the functional results were consistent with traditional techniques, which suggests the validity of the modification. Therefore, this is an alternative technique that achieves excellent functional results and successful withdrawal from corticosteroids, as well as preventing subluxation of the ulnar nerve. However, we emphasize the need for additional studies with larger and more diverse populations in order to further prove the efficiency of this modified technique.

\section{Acknowledgments}

The first author is grateful to Prof. C.R. Telles (Former Head and Director of the Division of Neurosurgery, State University of Rio de Janeiro) for giving him the opportunity to operate on these patients and to Prof. M. Parise (Head of the Division of Neurosurgery, State University of Rio de Janeiro) for allowing the use of the long-term data.

\section{References}

1. Assmus H, Antoniadis G, Bischoff C, Hoffmann R, Martini AK, Preissler $P$ et al. Cubital tunnel syndrome - a review and management guidelines. Cent Eur Neurosurg. 2011;72(2):90-8. https://doi.org/10.1055/s-0031-1271800

2. Bartels $\mathrm{RH}$. History of the surgical treatment of ulnar nerve compression at the elbow. Neurosurgery. 2001;49(2):391-9.

3. Seror P, Nathan PA. Relative frequency of nerve conduction abnormalities at carpal tunnel and cubital tunnel in France and the United States: importance of silent neuropathies and role of ulnar neuropathy after unsuccessful carpal tunnel syndrome release. Ann Chir Main Memb Super. 1993;12(4):281-5. https://doi.org/10.1016/S0753-9053(05)80027-4

4. Zlowodzki M, Chan S, Bhandari M, Kalliainen L, Schubert W. Anterior transposition compared with simple decompression for treatment of cubital tunnel syndrome. A meta-analysis of randomized, controlled trials. J Bone Joint Surg Am. 2007;89(12):2591-8. https://doi.org/10.2106/JBJS.G.00183

5. Martyn CN, Hughes RAC. Epidemiology of peripheral neuropathy. J Neurol Neurosurg Psychiatry. 1997;62(4):310-8. https://doi.org/10.1136/jnnp.62.4.310

6. Garbino JA. [Clinical management of diferents forms of compromising of neuropaty leprosy]. Hansen Int. 1998;98:93-9. Portuguese.

7. Job CK. Nerve damage in leprosy. Int J Lepr Other Mycobact Dis. 1989;57(2):532-9.

8. Husain S. Decompression of peripheral nerve trunks in leprosy prevents the development and progression of deformities? Indian J Lepr. 2013;85(4):163-9.

9. Ministério da Saúde (BR). [Manual of rehabilitation and surgery in leprosy]. 2a ed. Brasília, DF: Ministério da Saúde; 2008 [cited 2016 Jun 15]. (Cadernos de preenção e reabilitação em haseníase, vol 4). Available from: http://bvsms.saude.gov.br/bvs/ publicacoes/manual_reabilitacao_cirurgia_hanseniase.pdf

10. Bartels RH, Verhagen WI, Wilt GJ, Meulstee J, Rossum LG, Grotenhuis JA. Prospective randomized controlled study comparing simple decompression versus anterior subcutaneous transposition for idiopathic neuropathy of the ulnar nerve at the elbow: Part 1. Neurosurgery. 2005;56(3):522-30.https://doi.org/10.1227/01.NEU.0000154131.01167.03

11. Huang JH, Samadani U, Zager EL. Ulnar nerve entrapment neuropathy at the elbow: simple decompression. Neurosurgery. 2004;55(5):1150-3. https://doi.org/10.1227/01. NEU.0000140841.28007.F2 PMID:15509321

12. McGowan AJ. The results of transposition of the ulnar nerve for traumatic ulnar neuritis. J Bone Joint Surg Br. 1950;32-B(3):293-301.

13. Kim DH, Han K, Tiel RL, Murovic JA, Kline DG. Surgical outcomes of 654 ulnar nerve lesions. J Neurosurg. 2003;98(5):993-1004. https://doi.org/10.3171/jns.2003.98.5.0993

14. Kang HJ, Oh WT, Koh IH, Kim S, Choi YR. Factors influencing outcomes after ulnar nerve stability- based surgery for cubital tunnel syndrome: a prospective cohort study. Yonsei Med J. 2016;57(2):455-60. https://doi.org/10.3349/ymj.2016.57.2.455

15. Keith J, Wollstein R. A tailored approach to the surgical treatment of cubital tunnel syndrome. Ann Plast Surg. 2011;66(6):637-9. https://doi.org/10.1097/SAP.0b013e318219183d

16. Bimmler D, Meyer VE. Surgical treatment of the ulnar nerve entrapment neuropathy: submuscular anterior transposition or simple decompression of the ulnar nerve? Long-term results in 79 cases. Ann Chir Main Memb Super. 1996;15(3):148-57. https://doi.org/10.1016/S0753-9053(96)80004-4 
17. Biggs M, Curtis JA. Randomized, prospective study comparing ulnar neurolysis in situ with submuscular transposition. Neurosurgery. 2006;58(2):296-304. https://doi.org/10.1227/01.NEU.0000194847.04143.A1

18. Lane LB, Greenberg AS. Use of a fascial flap to stabilize an unstable ulnar nerve in its bed during in situ decompression. J Surg Orthop Adv. 2015;24(3):193-7.

19. Palmer BA, Hughes TB. Cubital tunnel syndrome.J Hand Surg Am. 2010;35(1):153-63. https://doi.org/10.1016/j.jhsa.2009.11.004
20. O'Driscoll SW, Horii E, Carmichael SW, Morrey BF. The cubital tunnel and ulnar neuropathy. J Bone Joint Surg Br. 1991;73(4):613-7.

21. Babusiaux D, Laulan J, Bouilleau L, Martin A, Adrien C, Aubertin A et al. Contribution of static and dynamic ultrasound in cubital tunnel syndrome. Orthop Traumatol Surg Res. 2014;100(4 Suppl):S209-12. https://doi.org/10.1016/j.otsr.2014.03.008

22. Okamoto M, Abe M, Shirai H, Ueda N. Morphology and dynamics of the ulnar nerve in the cubital tunnel. Observation by ultrasonography.J Hand Surg [Br]. 2000;25(1):85-9. https://doi.org/10.1054/jhsb.1999.0317 